\title{
DETERMINATION OF PRESSURE COEFFICIENT FOR A HIGH-RISE BUILDING WITH ATYPICAL GROUND PLAN
}

\author{
Soňa MEDVECKÁ ${ }^{1, *}$, Ol'ga IVÁNKOVÁ ${ }^{1}$, Marek MACÁK ${ }^{2}$, Vladimíra MICHALCOVÁ ${ }^{3}$ \\ ${ }^{1}$ Department of Structural Mechanics, Faculty of Civil Engineering, Slovak University of Technology, \\ Radlinského 11, 81005 Bratislava, Slovakia. \\ 2 Department of Mathematics and Descriptive Geometry, Faculty of Civil Engineering, Slovak \\ University of Technology, Radlinského 11, 81005 Bratislava, Slovakia. \\ ${ }^{3}$ Department of Structural Mechanics, Faculty of Civil Engineering, Technical University of Ostrava, \\ L. Podéště 1875/17, 70833 Ostrava - Poruba, Czech Republic. \\ corresponding author: sona.medvecka@stuba.sk.
}

\begin{abstract}
In this article, the results of pressure coefficient on the atypical object obtained by experimental measurements in a boundary layer wind tunnel (BLWT) of Slovak University of Technology in Bratislava (STU) and computational fluid dynamics simulation (CFD) are presented. The pressure coefficient is one of the most important parameters expressing the wind pressure distribution on the structure. The loading by wind can only be acquired by execution of detailed tests and numerical analyses [1].
\end{abstract}

\section{Keywords:}

Wind flowing

External wind pressure coefficients;

Laboratory measurements;

ANSYS and CFD simulations.

\section{Introduction}

Wind (air motion) is variable both in time and height. Moreover, its flow is not constant over the windward side of the building. In fact, authors in [2] stated that wind is a complicated phenomenon. It is mainly caused by turbulent flow. This phenomenon can be explained by irregular motion of single particles. Because of that, the emphasis must be given on a detailed study of statistical distributions of wind speeds and directions rather than to simple averages.

Nowadays, high-rise buildings are becoming an integral part of most urban landscapes [3]. It is caused by growing urbanization. It is very important to consider the effect of wind for a design of highrise buildings. The wind effects vary in accordance with the shape or height of designed buildings. It depends also on the surroundings which alter with the city development [4]. The effects of the wind on a building are usually determined using the external pressure coefficient $c_{p e}$. The Eurocode contains only the values $c_{p e}$ for two types of buildings. Structures with rectangular and circle plan are mentioned in the code. Presently, it is a serious problem for structural engineers - determination of pressure coefficient for a high-rise building with atypical ground plan and shapes. This paper deals with experimental determination of the $c_{p e}$ for the high-rise building with the cross-section of the letter "S" (Fig. 1). The experimentally determined values are compared to the values from CFD simulation and the values from the Eurocode 2. The comparison has been performed at four levels of the experimental model.

\section{Determination of external pressure coefficient by experiment in BLWT}

Dimensions of the model were $L \times W \times H=150 \times 150 \times 300 \mathrm{~mm}$, Fig.1. The scale of model was $1: 350$. Wind directions were $0^{\circ}, 45^{\circ}, 90^{\circ}$ and $135^{\circ}$. Total 56 measured points were used, being placed in four levels (in each of the 14 sensors). 

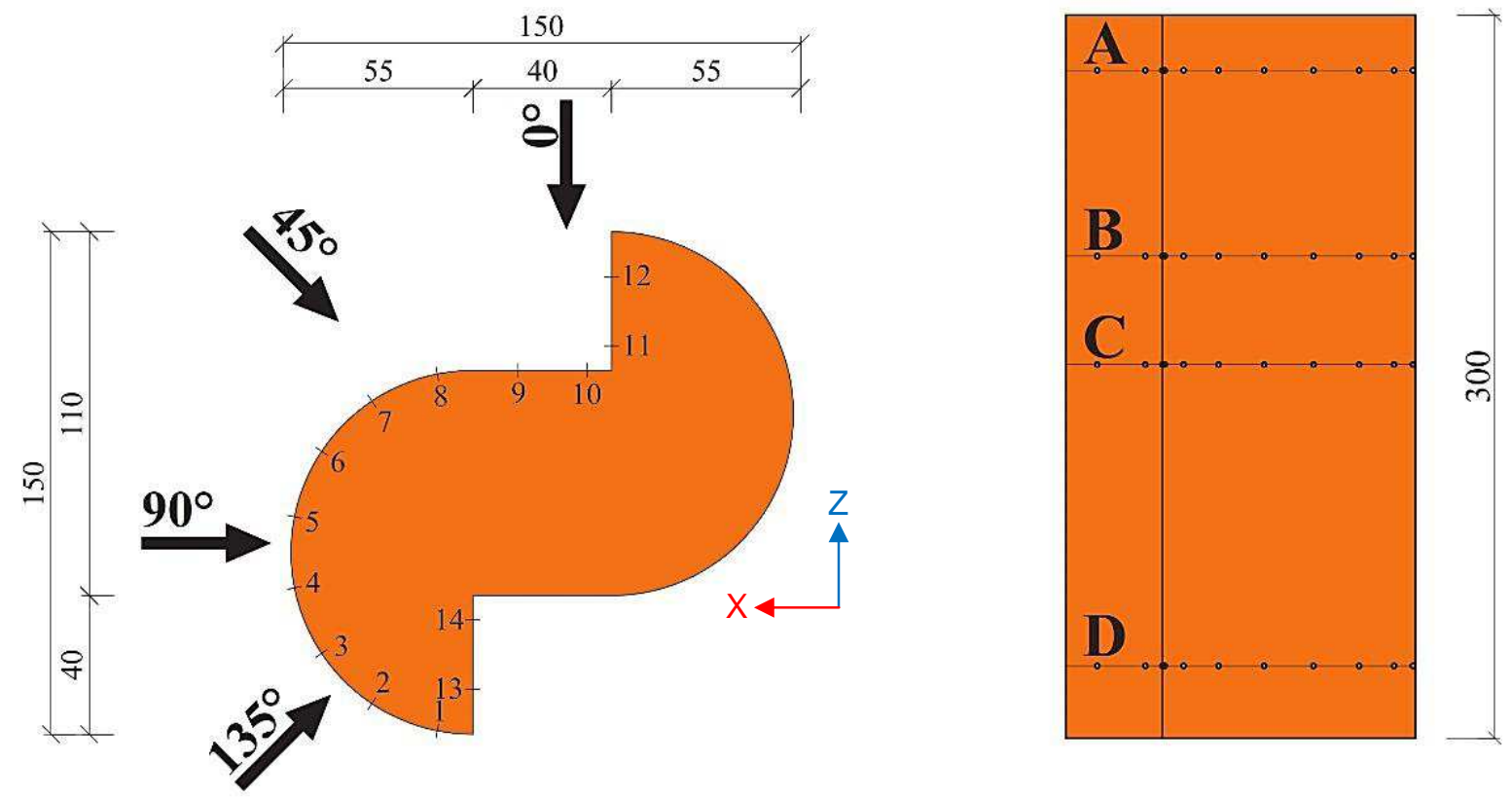

Fig. 1: Cross-section with measured points (with wind direction) and view of model.

Experimental measurements of external pressure coefficient were realized in the BLWT (Fig. 2) in the rear operating space. It is possible to develop the turbulent wind flow here. Speed of the wind can be varied from $0.3 \mathrm{~m} / \mathrm{s}$ up to $15 \mathrm{~m} / \mathrm{s}$ [5]. Terrain is classified between category III and IV. Other information about BLWT can be found in [6].
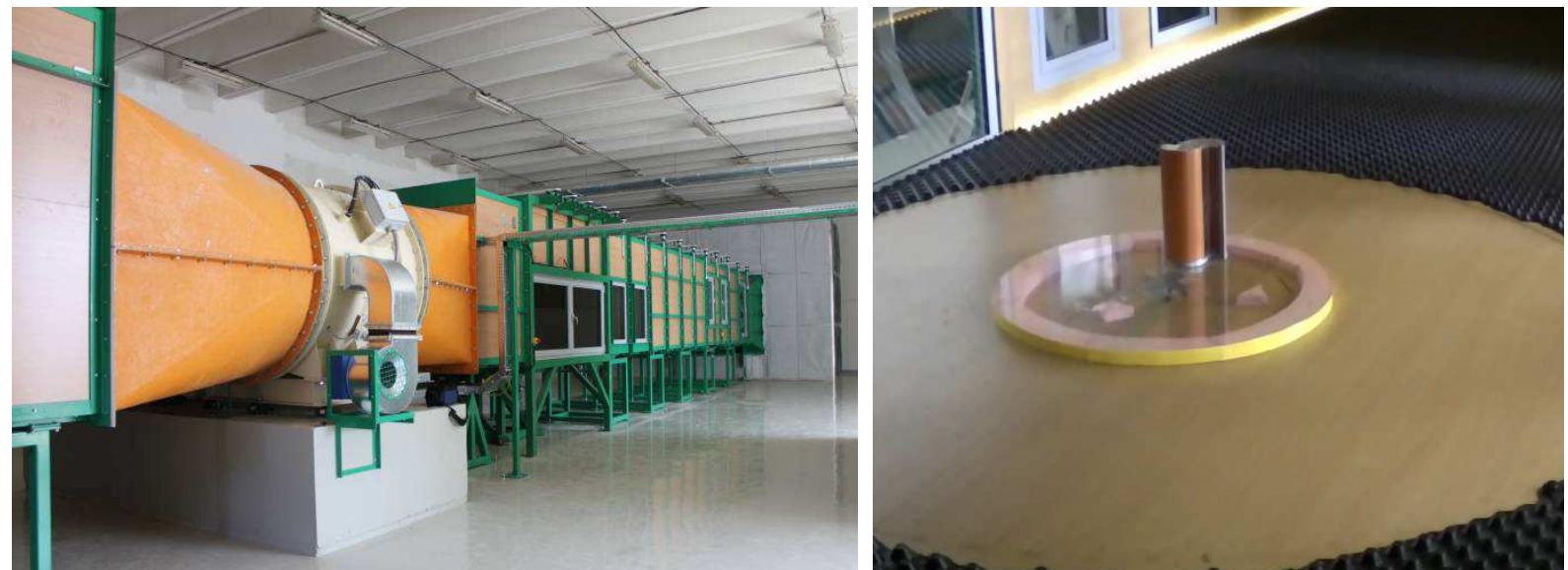

Fig. 2: The wind tunnel - BLWT STU and the experimental "S" model [6].

From pressure $p(z)$, the external pressure coefficient $c_{p e}$ according to (1) were calculated, while basic velocity pressure $q_{b}$ based on air density $\rho$ and reference wind velocity $v_{\text {ref }}$ in tunnel [7] was obtained.

$c_{p e}=\frac{p(z)}{a_{b}}=\frac{p(z)}{1 / 2 \cdot \rho \cdot v_{\text {ref }}^{2}}$

where: $v_{\text {ref }}=13.54 \mathrm{~m} / \mathrm{s} ; \rho=1.15 \mathrm{~kg} / \mathrm{m}^{3}$.

This procedure has been performed at four height levels of the " $\mathrm{S}$ " experimental model. Level A at the upper edge, at the reference height 2/3 $H$ (Level B), Level $\mathrm{C}$ in the middle and at the lower part (Level D). Fig. 3 shows the values of $c_{p e}$. These values have been obtained experimentally. 

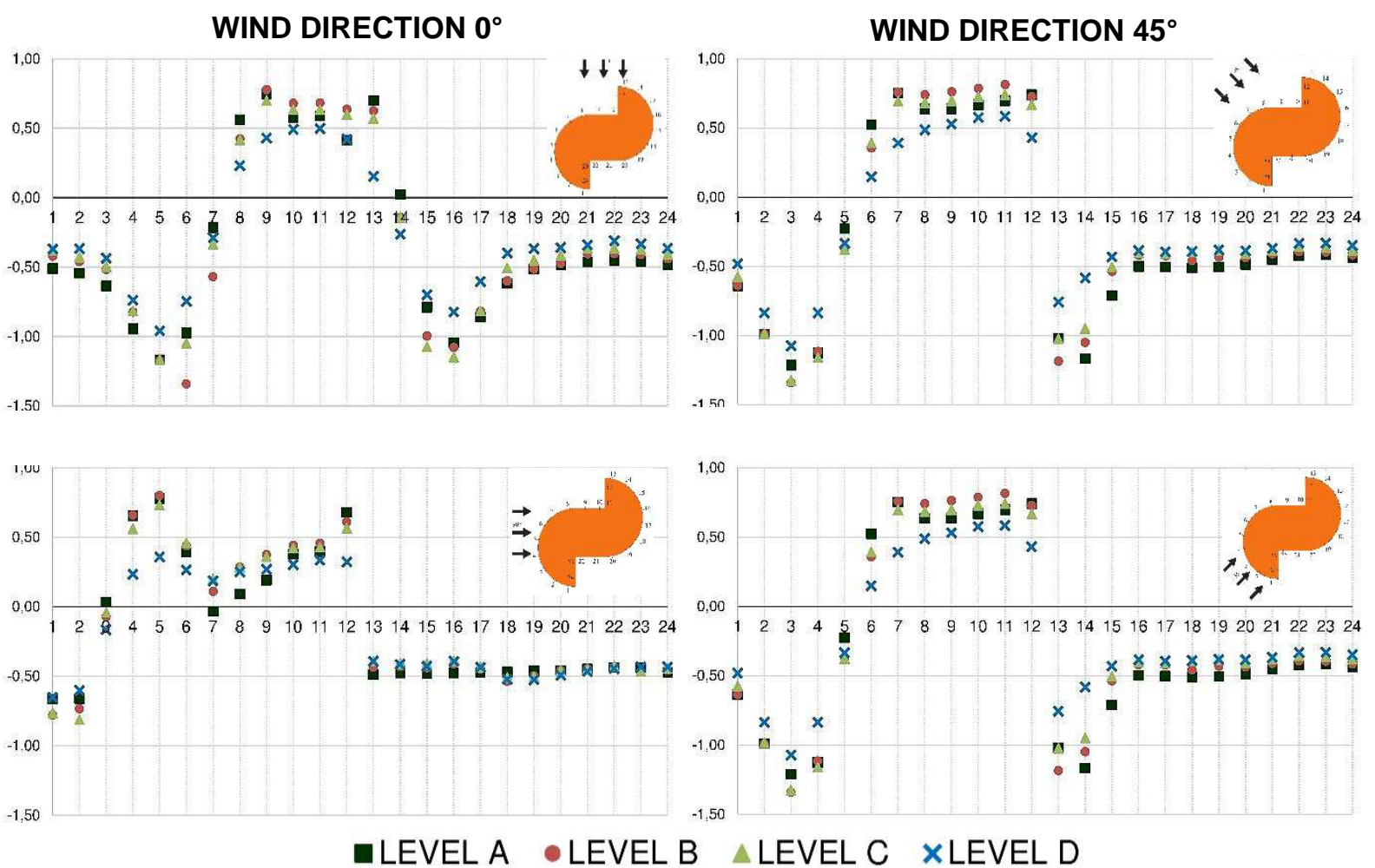

Fig. 3: Experimentally obtained values of $c_{p e}$ for the "S" model (Levels $A$ to $D$ ).

\section{Numerical simulations (CFD) - Calculation of external pressure coefficient}

All simulations were run in ANSYS Fluent [8] using SST $k$ - $\omega$ model. The computational domain had dimensions $L \times W \times H=4.7 \times 2.3 \times 18 \mathrm{~m}$ and the model, illustrated in Fig. 1, was placed $1 \mathrm{~m}$ behind the inlet surface. The recommended maximum blockage of $3 \%$ also states that all the distance conditions were accomplished $[9,10]$. Namely, distance from the building to the side, to the outlet, to the inlet and to the top of the domain. A small subdomain with dimensions $1.8 \times 0.35 \times 0.4 \mathrm{~m}$ was created, with refined size of mesh.

Three types of mesh to perform grid sensitivity were created. All grids were generated using cutcell elements. First mesh was generated using course relevance center (Fig. 4a). The element size on surface of the model was $0.02 \mathrm{~m}$ with soft behavior while the inflation was applied with 5 layers with a growth rate of $10 \%$. The element size in small refine subdomain was $0.08 \mathrm{~m}$. The inflation was also applied on bottom boundary with 2 layers with growth rate of $10 \%$. All other settings were left on default. 32471 elements with 36984 nodes were generated. Second mesh was generated using medium relevance center (Fig. 4b). The element size on surface of the model was $0.01 \mathrm{~m}$ with soft behavior while the inflation was applied with 5 layers with growth rate of $10 \%$. The element size in small refine subdomain was $0.04 \mathrm{~m}$. The inflation was also applied on bottom boundary with 2 layers with growth rate of $10 \%$. All other settings were left on default. 63987 elements with 71306 nodes were generated. Third mesh was generated using fine relevance center (Fig. 4c). The size of the surface element was $0.005 \mathrm{~m}$ with soft behavior while the inflation was applied with 5 layers with growth rate of $10 \%$. The element size in small refine subdomain was $0.02 \mathrm{~m}$. The inflation was also applied on bottom boundary with 2 layers with growth rate of $10 \%$. All other settings were left on default. Finally, 232809 nodes were generated. These nodes represented 212749 elements. 


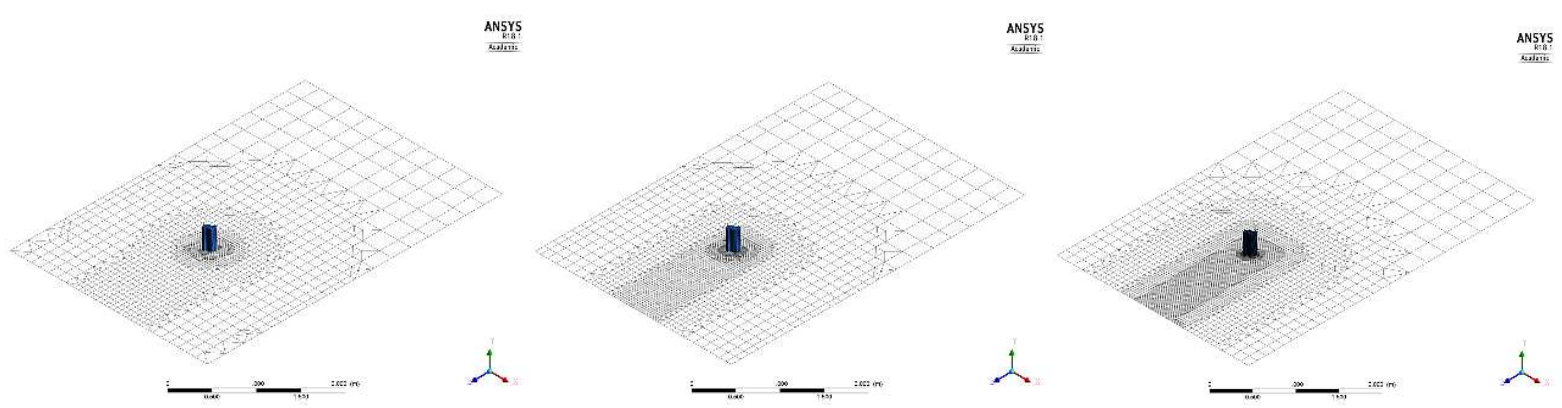

Fig. 4: Illustration of the mesh of bottom boundary for different mesh refinement.

The inlet boundary conditions of the domain are defined by the logarithmic vertical profile

$u(z)=\frac{u^{*}}{\kappa} \ln \frac{z+z_{0}}{z_{0}}$

where $u(z)$ represents the mean wind velocity and $u^{*}$ represents shear velocity, $z$ is elevation, $z_{0}$ is aerodynamic roughness height and $\kappa$ is von Karman constant. It is recommended to use aerodynamic roughness height in tunnel scale $z_{0}=0.00233$ for wind simulation in SvF STU Wind Tunnel Laboratory in Bratislava. The $k$ - $\omega$ model inputs are based on turbulent kinetic energy $k$ and specific turbulence dissipation rate $\omega$ as follows:

$$
\begin{gathered}
k=\frac{u^{* 2}}{\sqrt{C_{\mu}}}, \\
\omega(z)=\frac{\varepsilon(z)}{k},
\end{gathered}
$$

where $C_{\mu}$ is model constant and turbulence dissipation rate $\varepsilon$ is given by

$$
\varepsilon(z)=\frac{u^{* 3}}{\kappa\left(z+z_{0}\right)} .
$$

The outlet boundary is defined as pressure outflow and the side and upper boundary as zero gradient or symmetry. The bottom boundary is simulated as a through wall. For through wall the method proposed in [11] is used

$$
k_{S}=\frac{E \cdot z_{0}}{c_{s}},
$$

where $k_{s}$ is the roughness height of wall function, $c_{s}$ is the roughness constant of wall function and $E=9.79$ is the log law of the wall constant.

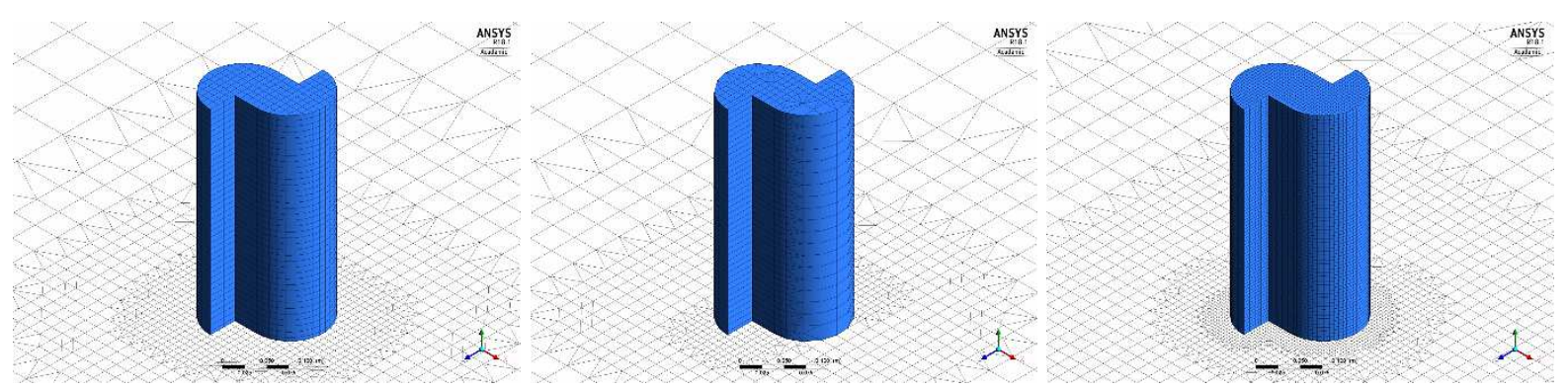

Fig. 5: Detailed views of the computational grids - three cases. 
All simulations ran as steady pressure-based. SIMPLE pressure-velocity coupling scheme with second order spatial discretization method was used for solution. Solution was initialized using hybrid initialization with default setting. The calculations were performed using a PC with one Intel Core i7-3930K 3.2 GHz processor and 32 GB DDR3 memory.

The grid convergence is presented in Fig. 6, while the calculation grid with elements size $0.005 \mathrm{~m}$ corresponds the most with the experiment results. For this reason, only the results obtained using the finest grid, will be presented. The obtained values of $c_{p e}$ from the CFD calculations are shown in Figs. 7 - 10.

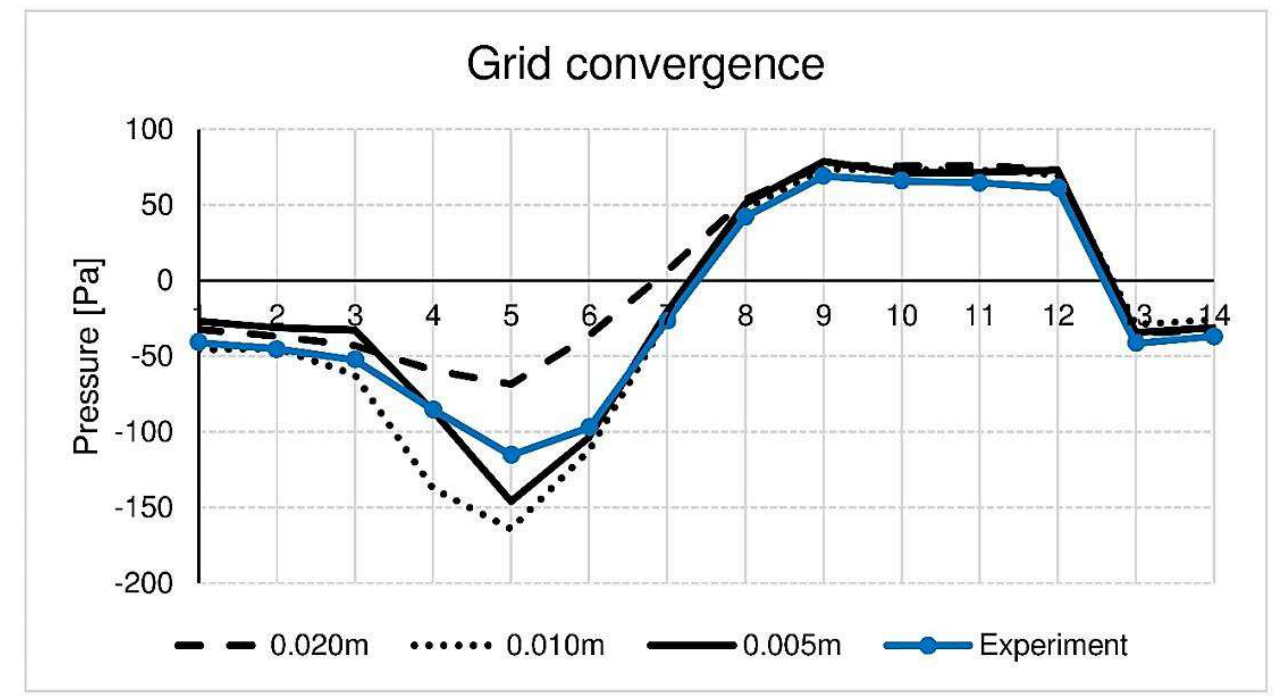

Fig. 6: Grid convergence Level C, wind direction $0^{\circ}$.
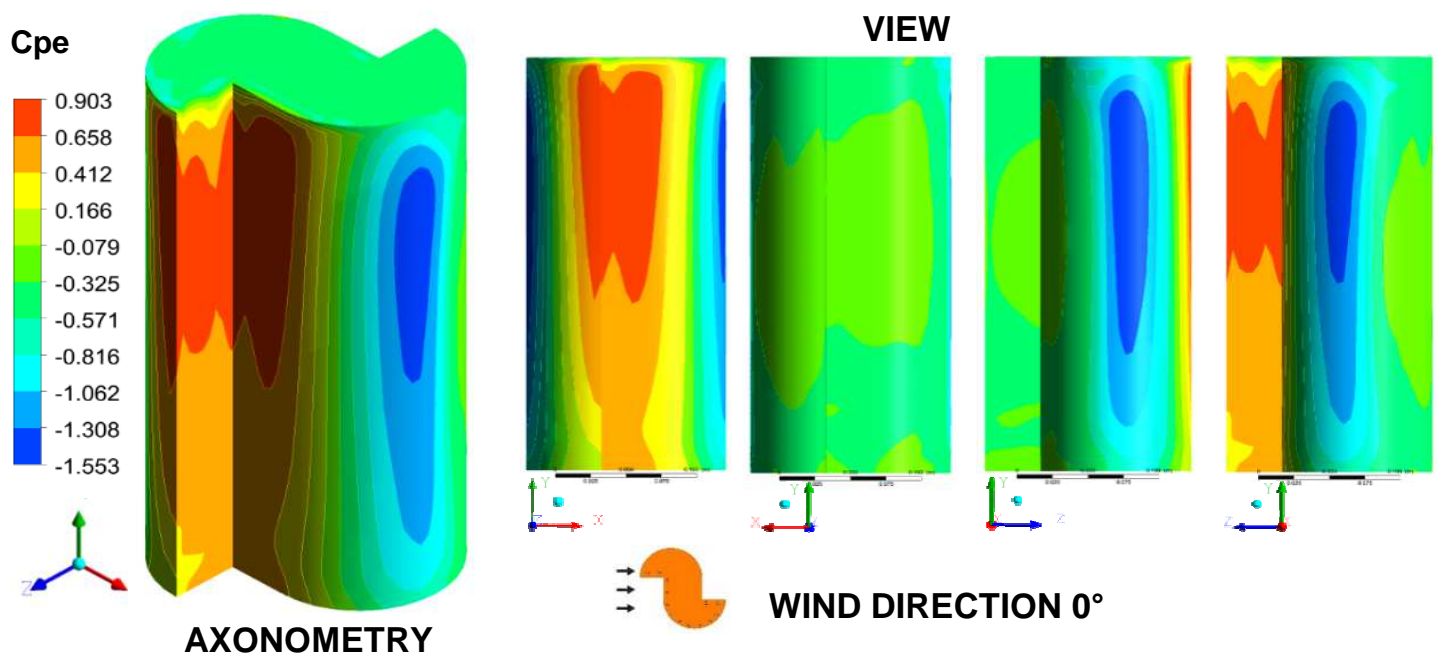

AXONOMETRY

\section{WIND DIRECTION $0^{\circ}$}

Fig. 7: Values of $c_{p e}$ obtained from CFD for direction $0^{\circ}$. 


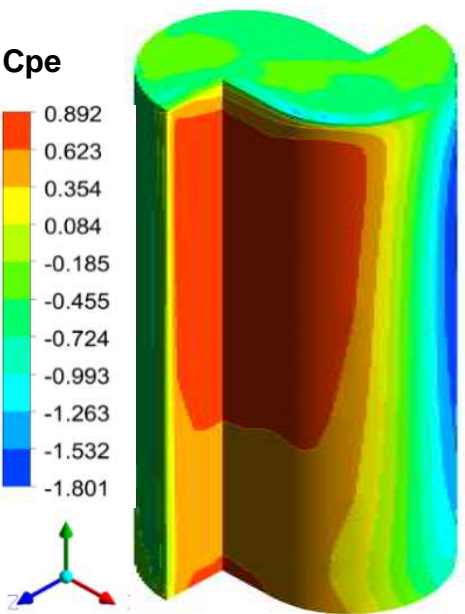

AXONOMETRY
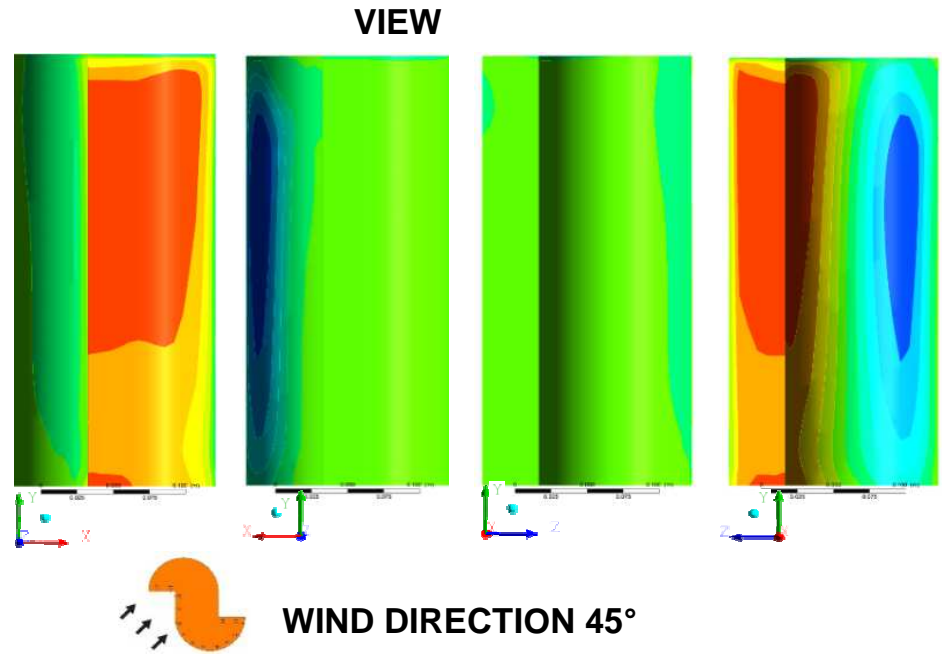

WIND DIRECTION 45

Fig. 8: Values of $c_{p e}$ for models from CFD simulation (front view, rear view, axonometry) - $45^{\circ}$.
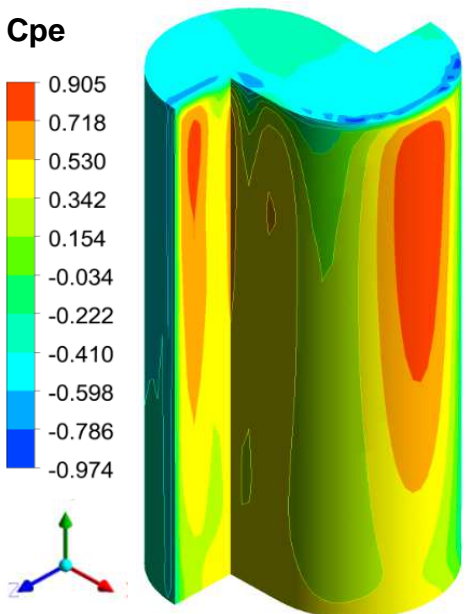

AXONOMETRY

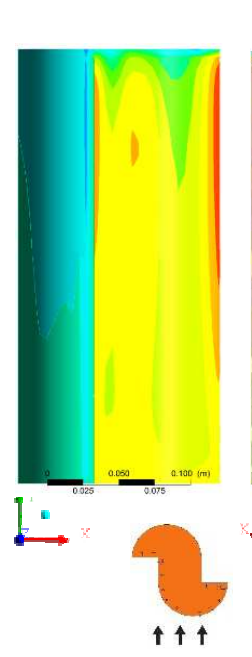

VIEW
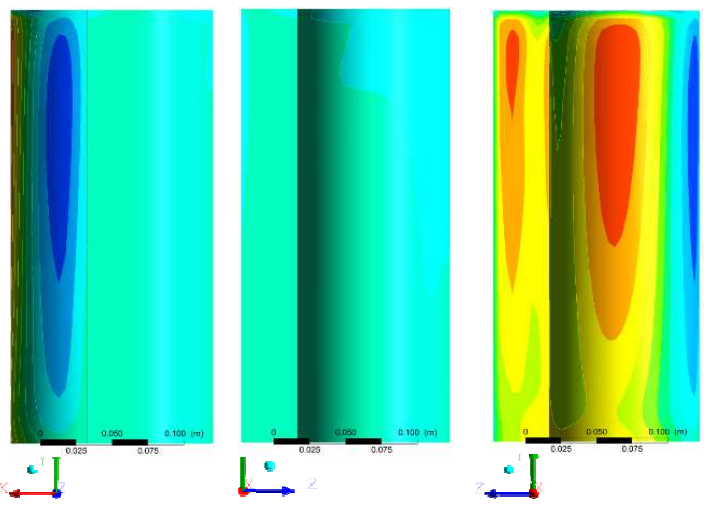

\section{WIND DIRECTION $90^{\circ}$}

Fig. 9: Values of $c_{p e}$ for models from CFD simulation (front view, rear view, axonometry) - $90^{\circ}$.
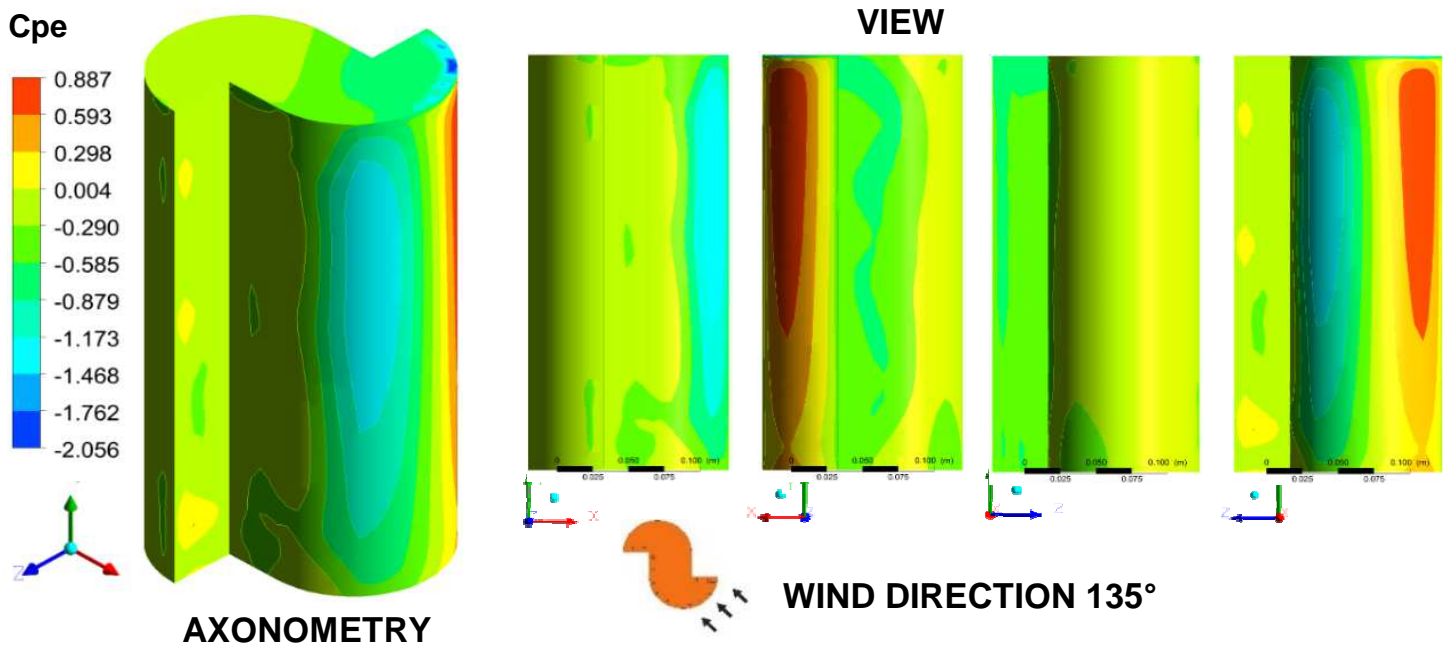

Fig. 10: CFD Simulations - Values of $c_{p e}$ for numerical models (axonometry on the left, front and rear views) $-135^{\circ}$. 


\section{Conclusion}

The comparison of coefficient $c_{p e}$ obtained by experimental measurements and computational fluid dynamics simulation for four wind directions is presented in Table 1. The extreme values of $c_{p e}$ were $-1.34(-1.79)$ and $0.81(0.85)$, which were occurred in level B. In comparison between CFD simulation and experiment, these results were in a good agreement and smaller varieties were only observed in the induction area.

Table 1: Comparison of extreme values of $c_{p e}$ for the "S" model (Level A, B, C and D).

\begin{tabular}{|c|c|c|c|c|c|c|c|c|}
\hline Extreme value & \multicolumn{2}{|c|}{ Level A } & \multicolumn{2}{c|}{ Level B } & \multicolumn{2}{c|}{ Level C } & \multicolumn{2}{c|}{ Level D } \\
\hline \multirow{2}{*}{ Experiment } & 0.78 & $90^{\circ}$ & $\mathbf{0 . 8 1}$ & $45^{\circ}$ & 0.74 & $45^{\circ}$ & 0.58 & $45^{\circ}$ \\
\cline { 2 - 10 } & -1.21 & $45^{\circ}$ & $-\mathbf{1 . 3 4}$ & $0^{\circ} / 45^{\circ}$ & -1.32 & $45^{\circ}$ & -1.07 & $45^{\circ}$ \\
\hline \hline \multirow{2}{*}{ CFD Simulation } & $\mathbf{0 . 8 5}$ & $0^{\circ}$ & 0.82 & $45^{\circ}$ & 0.76 & $45^{\circ}$ & 0.61 & $45^{\circ}$ \\
\cline { 2 - 9 } & -1.33 & $0^{\circ}$ & $-\mathbf{- 1 . 7 9}$ & $45^{\circ}$ & -1.73 & $45^{\circ}$ & -1.29 & $45^{\circ}$ \\
\hline \hline \multirow{2}{*}{ Difference [\%] } & \multicolumn{2}{|c|}{$8.24 \%$} & \multicolumn{2}{|c|}{$1.22 \%$} & \multicolumn{2}{|c|}{$2.63 \%$} & \multicolumn{2}{c|}{$4.92 \%$} \\
\cline { 2 - 8 } & \multicolumn{2}{|c|}{$9.02 \%$} & \multicolumn{2}{|c|}{$25.14 \%$} & \multicolumn{2}{c|}{$23.70 \%$} & \multicolumn{2}{c}{$17.05 \%$} \\
\hline
\end{tabular}

The most unfavorable wind direction was at an angle of $45^{\circ}$. Comparison of $c_{p e}$ for level $\mathrm{B}$ this direction was made in cross-section in measured points, Fig. 11.

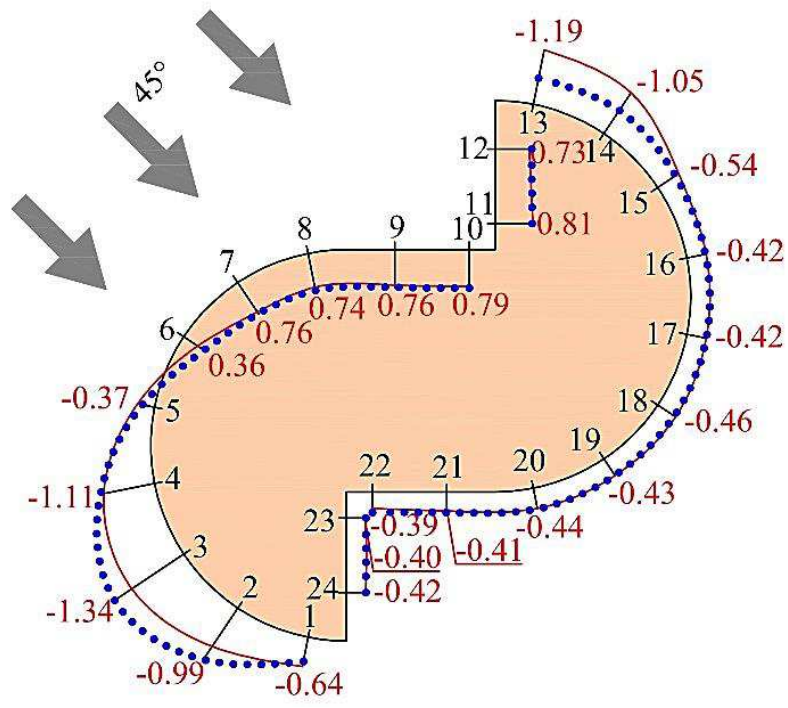

\section{EXPERIMENT}

CFD SIMULATION

Fig. 11: Comparison of experimentally and numerically obtained $c_{p e}$ at Level B for wind direction $45^{\circ}$.

\section{Acknowledgement}

This paper was written with support of Slovak Grant Agency VEGA. Registration numbers of the projects are 1/0412/18,1/0608/15 and APVV-15-0522 and by the project of "Conceptual development of science and research activities 2018" on the Faculty of Civil Engineering, VŠB-TU Ostrava and by the Ministry of Education, Youth and Sports from the Large Infrastructures for Research, Experimental Development and Innovations project „IT4Innovations National Supercomputing Center LM2015070“.

\section{References}

[1] ZHAO, X. - DING, J. M. - SUN, H. H.: Structural design of Shanghai Tower for wind loads. Procedia Engineering, Vol. 14, 2011, pp. 1759 - 1767.

[2] TARANATH, B. S.: Reinforced concrete design of tall buildings, Boca Raton: CRSI/Concrete Reinforcing Steel Institute, 2010, p. 989.

[3] ELSHAER, A. - GAIROLA, A. - ADAMEK, K. - BITSUAMLAK, G.: Variations in wind load on tall buildings due to urban development. Sustainable Cities and Society, Vol. 34, 2017, pp. 264 - 277. 
[4] KOTRASOVÁ, K. - HEGEDÜŠOVÁ, I. - HARABINOVÁ, S. - PANULINOVÁ, E. KORMANÍKOVÁ, E.: The possible causes of damage to concrete tanks, numerical experiment of fluid-structure-soil interaction (Book Chapter). Key Engineering Materials, Vol. 738, 2017, pp. 227 237.

[5] HUBOVÁ, O. - MACÁK, M. - KONEČNÁ, L. - CIGLAN, G.: External Pressure Coefficients on the atypical high-rise building - computing simulation and measurements in wind tunnel. Procedia Engineering, Vol. 190, 2017, pp. 488 - 495.

[6] HUBOVÁ, O. - KONEČNÁ, L.: Experimental Determination of Wind Flowing around a Building Configuration. Procedia Engineering, Vol. 161, 2016, pp. 1845 - 1851.

[7] MICHALCOVÁ, V. - LAUSOVÁ, L. - KOLOS, I.: Numerical modelling of flow around thermally loaded object. Dynamics of Civil Engineering and Transport Structures and Wind Engineering DYN-WIND'2017, Matec Web of Conferences, Vol. 107, 2017.

[8] ANSYS Inc.: ANSYS Fluent User's Guide, Release 18 January 2017.

[9] TOMINAGA, Y. - MOCHIDA, A. - YOSHIE, R. - KATAOKA, H. - NOZU, T. - YOSHIKAWA, M. SHIRASAWA, T.: AlJ guidelines for practical applications of CFD to pedestrian wind environment around buildings. Journal of Wind Engineering and Industrial Aerodynamics, Vol. 96, Iss. 10 - 11, 2008, pp. 1749 - 1761.

[10] FRANKE, J. - HELLSTEN, A. - SCHLÜNZEN, H. - VARISSIMO, B.: Best practice guideline for the CFD simulation of flows in the urban environment. COST Office Brussels, 2007.

[11] BLOCKEN, B. - STATHOPOULOS, T. - CARMELIET, J.: CFD simulation of the atmospheric boundary layer-wall function problems. Atmospheric Environment Vol. 41, 2017, pp. 238 - 252. 